\title{
Polymeric biomaterial hydrogels. I. Behavior of some ionotropic cross-linked metal-alginate hydrogels especially copper-alginate membranes in some organic solvents and buffer solutions
}

\author{
Refat Hassan $^{1 \#}$, Fahd Tirkistani ${ }^{2}$, Ishaq Zaafarany ${ }^{2}$, Ahmed Fawzy ${ }^{1,2}$, Mohamed Khairy ${ }^{3}$, Sayed Iqbal $^{4}$ \\ ${ }^{1}$ Chemistry Department, Faculty of Science, Assiut University, Assiut, Egypt \\ ${ }^{2}$ Chemistry Department, Faculty of Applied Sciences, Umm Al-Qura University, Makkah, KSA \\ ${ }^{3}$ Chemistry Department, Faculty of Science, Benha University, Benha, Egypt \\ ${ }^{4}$ Chemistry Department, Saifia College of Science and Education, Bhopal, India \\ Email: ${ }^{\text {rmhassan2002@yahoo.com }}$
}

Received 22 August 2012; revised 28 September 2012; accepted 16 October 2012

\begin{abstract}
The change in rheological and mechanical properties for some ionotropic cross-linked metal-alginate hydrogel complexes in particularly copper-alginate membranes in the presence of some organic solvents (benzene, toluene, xylene, carbon tetrachloride, acetone, chloroform, dichloroethane, isobutyl alcohol and ethyl alcohol) or buffer solutions (acetates, borates and universal buffers) have been investigated. The experimental results showed a remarkable tendency of the studied hydrogels for shrinking in polar solvents, whereas no influence was observed for the hydrogels in non-polar solvents. On the other hand, the gels were found to swell or shrink in the buffer solutions depending on the $\mathrm{pH}$ of the buffer used. The swelling extent for hydrogel spheres was found to decrease in the order $\mathrm{Cu}>\mathrm{Ba} \approx \mathrm{Ca}>\mathrm{Zn}>\mathrm{Pb}$-alginates in universal buffers of $\mathrm{pH}=5.33$. The factors affected this behavior have been examined and discussed.
\end{abstract}

Keywords: Biomaterials; Hydrogels; Swelling;

Shrinking; Metal-Alginates; Biocatalysts

\section{INTRODUCTION}

Hydrogels that exhibit volume changes under the influence of environmental changes such as the solvent composition, $\mathrm{pH}, \mathrm{UV}$ and visible light and surfactants, are promising intelligent biotechnological materials [1].

\footnotetext{
*This article is dedicated to the memory of Professor Mohamed A. Abd-Alla, Professor of Polymer Chemistry, Faculty of Science, Assiut University.

${ }^{\#}$ Corresponding author.
}

These polymeric biomaterials are widely used in many potential applications such as drug delivery, tissues engineering, biomaterial sensing, skin grafting, medical adhesive, biocatalysts and textiles [2].

Recently, there is an increasing interest for production of ethanol on a large scale in industrial technology since ethanol is considered as an alternative fuel to the current fossil fuels in the whole world. The well-known traditional method for ethanol manufacturing is the use of sugar and yeast, in addition to other alternative techniques based on using the microorganisms for such conversion. Nowadays, calcium-alginate spheres are frequently used as biocatalysts in the immobilization systems [3].

Torres et al. [4] studied the behavior of Ca-alginate spheres in some pure solvents as well as in water-solvent mixtures. They reported that the gel particles were suffered different changes depending on the nature of the solvent used. It has been noticed that the physical properties such as the dielectric constants and the polarity are not capable to explain the behavior observed in such used solvents, except in water-ethanol mixtures.

Metal-alginates were frequently prepared by sol-gel transformation processes through addition of alginate sols to electrolyte solutions of polyvalent metal ions [5-7]. The kinetics and mechanism of such sol-gel transformation (gelation) have been investigated in details for the first time by us earlier [8-12]. Again, the diffusion controls affected such gelation processes were examined and reported elsewhere $[13,14]$.

In view of the aforementioned aspects and our interesting on studies of physicochemical properties of some metal-alginate hydrogel biomaterials [15-25], the present work seems to be of interest with the aims at shedding further highlights on the behavior of metal-alginates par- 
ticularly copper-alginate gel membranes in various solvents and buffer solutions and to compare the results obtained with that reported for calcium-alginate spheres in both aqueous [3], and in non-aqueous solutions.

\section{EXPERIMENTAL}

\subsection{Materials}

Sodium alginate (Cica-Reagent Chem. Co.) was used in the present work. The degree of substitution was found to be $4.34 \mathrm{~m} \mathrm{~mol} \cdot \mathrm{g}^{-1}\left(0.95 \mathrm{~mol} \cdot \mathrm{mol}^{-1}\right)$. The measured viscosities using an Ubbelhode viscometer for a $4 \%$ alginate sol in water $(\mathrm{w} / \mathrm{w})$ were found to be 2.78 and $9.87 \mathrm{dL} \cdot \mathrm{g}^{-1}$ for the inherent and reduced viscosities, respectively, at $25^{\circ} \mathrm{C}$.

All other chemicals used were of Analar (BHD) grade. Doubly distilled conductivity water was used in all preparations.

\subsection{Preparation of Sodium-Alginate Sols}

Sodium alginate sols of different concentrations $(2 \%, 3 \%$ and $4 \%)$ in water $(\mathrm{w} / \mathrm{w})$ were prepared as described earlier [8-13]. This process was performed by stepwise addition of the alginate powder reagent to doubly distilled water whilst rapidly stirring the water to avoid the formation of lumps, which swell with difficulty. The prepared alginate sols were left at room temperature $\left(25^{\circ} \mathrm{C}\right)$ for about $24 \mathrm{~h}$ in order to become air-bubbles free before used.

\subsection{Preparation of Buffer Solutions}

Acetate, borate and universal buffers were prepared as described elsewhere [26]. The Ph's of the buffer solutions was measured by using a digital $\mathrm{pH}$-meter.

\subsection{Preparation of Cross-Linked Metal-Alginate Ionotropic Hydrogels}

Cross-linked metal-alginate ionotropic hydrogels can be prepared in different shapes such as spheres $[13,14$,
$17,18]$, columns $[13,27]$ or membranes $[9,12,28]$ depending on the apparatus used.

\subsubsection{Preparation of Metal-Alginate Spheres}

Hydrogel spheres can be prepared by dropping sodium-alginate sols into electrolyte solutions of polyvalent metal ions using a dropper or a syringe.

In our case, we used a special glass syringe for preparation of $\mathrm{Ca}, \mathrm{Ba}, \mathrm{Cu}, \mathrm{Zn}$ and $\mathrm{Pb}$-alginate hydrogel spheres as described earlier [13,14,17,18]. After completion of the sol-gel transformation process, the formed spheres were carefully removed from the containers of metal ion electrolytes (beakers or conical flasks) and washed with deionized water several times until the resultant washings became free from non-chelated metal ions. The hydrogel spheres were then kept in doubly distilled conductivity water for use.

For each alginate sol and metal ion electrolyte, the following precautions were taken into consideration to maintain the size and shape of all alginate sol droplets constant as far as possible 1) the volume of the alginate sol inside the syringe and the distance of the syringe tip from the surface of the electrolyte were kept constants; 2) the force exerted upon the piston of the syringe was maintained fixed; and 3) the same syringe was used as a dropper in all preparations.

The water content, number of the coordinated water molecules, relaxation time, mechanical properties along with other rheological properties of these metal-alginate hydrogel spheres are summarized in Table 1. All cited data are an average of five experimental runs (within experimental errors of $\pm 5 \%$ ).

\subsubsection{Preparation of Copper-Alginate Membranes}

Ionotropic membranes for cross-linked copper-alginate hydrogels were prepared as described elsewhere [9, $12,28]$. This process was performed by smearing the internal walls of some Petri-dishes of $10 \mathrm{~cm}$ diameter and $3 \mathrm{~cm}$ in height with a very thin layer of the used alginate sol. The Petri-dishes were placed in an electric oven at

Table 1. Some rheological and mechanical properties, water content, relaxation time and the rate of gelation for metal-alginate spheres.

\begin{tabular}{|c|c|c|c|c|c|c|c|c|c|}
\hline \multirow{2}{*}{ Metal-alginate } & \multirow{2}{*}{$\Delta \tau, \min$} & \multirow{2}{*}{$\begin{array}{c}10^{4} \mathrm{R}_{\mathrm{g}}, \mathrm{M}^{-1} \cdot \mathrm{S}^{-1} \\
{[\mathrm{Alg}]=2 \%, 25^{\circ} \mathrm{C}}\end{array}$} & \multicolumn{2}{|c|}{ Water content } & \multirow{2}{*}{$\begin{array}{l}10^{2} \text { Droplet } \\
\text { weight, gm }\end{array}$} & \multirow{2}{*}{$\begin{array}{l}10^{2} \text { Droplet } \\
\text { volume, } \mathrm{cm}^{3}\end{array}$} & \multirow{2}{*}{ Elasticity } & \multirow{2}{*}{ Transparey } & \multirow{2}{*}{$\mathrm{xH}_{2} \mathrm{O}$} \\
\hline & & & $2 \%$ & $4 \%$ & & & & & \\
\hline Ca-alginate & 33.48 & 1.33 & 97.78 & 95.12 & 97.78 & 2.97 & elastic & transparent & 3 \\
\hline $\mathrm{Cu}$-alginate & 33.11 & 3.53 & 97.46 & 94.56 & 97.46 & 3.29 & elastic & transparent & 3 \\
\hline Zn-alginate & 30.03 & 1.05 & 97.14 & 94.88 & 97.14 & 3.09 & elastic & transparent & 3 \\
\hline Ba-alginate & 30.48 & 3.78 & 96.56 & 93.04 & 96.56 & 3.46 & elastic & transparent & 3 \\
\hline Pb-alginate & 18.08 & 3.35 & 96.76 & 93.76 & 96.76 & 2.87 & elastic & transparent & 2 \\
\hline
\end{tabular}


$80^{\circ} \mathrm{C}-85^{\circ} \mathrm{C}$ for about $20 \mathrm{~min}$, cooled and then were filled with alginate sol of known concentration. Afterward, these Petri-dishes were gently and very care fully immersed in $\mathrm{Cu}^{2+}$ electrolyte solution of known concentration. As the alginate sol gets in contact with the $\mathrm{Cu}^{2+}$ ion electrolyte, a thin layer of primary membrane is formed on the surface of the alginate sol inside the Petri-dish. Then, an exchange process between the $\mathrm{Na}^{+}$ counter ions of alginate macromolecule sol and that of $\mathrm{Cu}^{2+}$ ions of electrolyte solution will take place with growing a multilayer membrane for $\mathrm{Cu}$-alginates (polymembrane). The growth of the membrane for about $2 \mathrm{~cm}$ in thickness takes about $10 \mathrm{~h}$ for $2 \%$ alginate sol. The time of growth increases with increasing the sol concentration and vice versa with respect to the concentration of $\mathrm{Cu}^{2+}$ ion electrolyte.

Then, the formed polymembranes were carefully removed from the internal walls of the Petri-dishe and washed frequently with deionized water until the resul tant washings became free from non-chelated $\mathrm{Cu}^{2+}$ ions. The washed membranes were then kept in doubly distilled conductivity water for use.

\subsection{Behavior of Cu-Alginate Membranes in Various Solvents and Buffers}

Copper-alginate membranes were cut into cubes of the same dimensions and their outer surfaces were blotted quickly by means of filter paper strips and then immersed into Erlenmeyer flasks containing $50 \mathrm{ml}$ of either the solvent or buffer solutions to be used. The change in the volume was followed periodically until it reached a constant value ( 5 - 7 days). The results are summarized in Tables 2-5 and Figures 1-4, respectively.

Some experimental runs were performed using metal-alginate hydrogels in the sphere forms $(2 \%)$ in universal buffers of $\mathrm{pH}=5.33$. The results are summa rized in Table 6 and Figure 5, respectively.

Table 2. The effect of some organic solvents on the volume of copper-alginate gel membranes (4\%).

\begin{tabular}{|c|c|c|c|c|c|c|}
\hline \multirow{2}{*}{ Solvent } & \multirow{2}{*}{ Volume of solvent, $\mathrm{mL}$} & \multirow{2}{*}{ pH of solvent } & \multirow{2}{*}{ Volume of gel, mL } & \multicolumn{3}{|c|}{ Changing in the gel volume $\left(\mathrm{cm}^{3}\right)$ with time $/ \mathrm{h}$} \\
\hline & & & & $24 \mathrm{~h}$ & $48 \mathrm{~h}$ & $120 \mathrm{~h}$ \\
\hline Isobutyl alcohol & 50 & 3.12 & 5 & 3.5 & 3.5 & 3.5 \\
\hline Toluene & 50 & 3.48 & 5 & 5.0 & 5.0 & 5.0 \\
\hline Chloroform & 50 & 3.52 & 5 & 4.0 & 4.0 & 4.0 \\
\hline Xylene & 50 & 4.41 & 5 & 5.0 & 5.0 & 5.0 \\
\hline Ethyl alcohol & 50 & 5.69 & 5 & 3.5 & 3.5 & 3.5 \\
\hline Dichloroethane & 50 & 6.40 & 5 & 3.5 & 3.5 & 3.5 \\
\hline Acetone & 50 & 6.60 & 5 & 4.0 & 4.0 & 4.0 \\
\hline Benzene & 50 & - & 5 & 5.0 & 5.0 & 5.0 \\
\hline Carbon tetrachloride & 50 & - & 5 & 5.0 & 5.0 & 5.0 \\
\hline
\end{tabular}

Table 3. The behavior of copper-alginate gel membranes in borate and acetate buffer solutions.

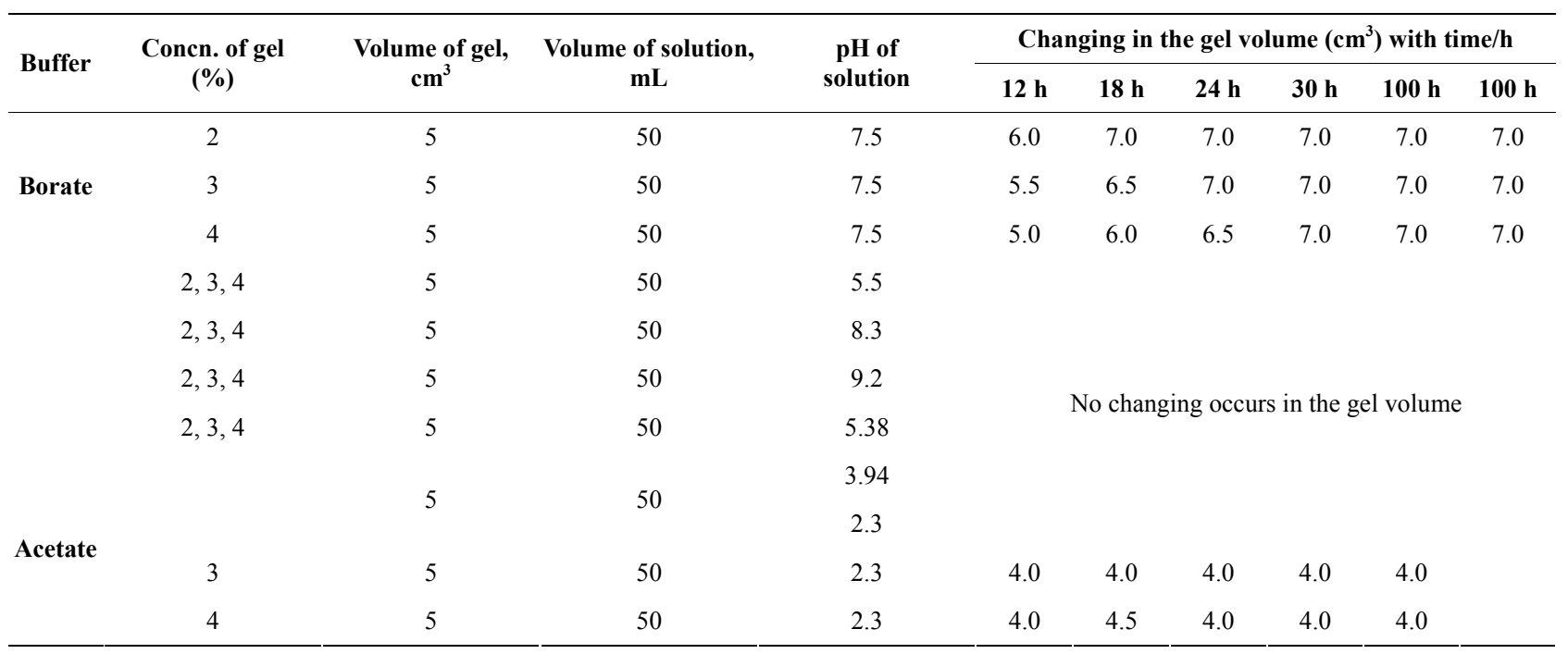


Table 4. The behavior of copper-alginate gel membranes in universal buffer solution.

\begin{tabular}{|c|c|c|c|c|c|c|c|c|c|c|}
\hline \multirow{2}{*}{$\begin{array}{c}\text { Concn. of gel } \\
(\%)\end{array}$} & \multirow{2}{*}{$\begin{array}{c}\text { Volume of gel, } \\
\mathrm{cm}^{3}\end{array}$} & \multirow{2}{*}{$\begin{array}{c}\text { Volume of } \\
\text { solution, } \mathrm{mL}\end{array}$} & \multirow{2}{*}{$\begin{array}{c}\text { pH of } \\
\text { solution }\end{array}$} & \multicolumn{7}{|c|}{ Changing in the gel volume $\left(\mathrm{cm}^{3}\right)$ with time $/ \mathrm{h}$} \\
\hline & & & & $24 \mathrm{~h}$ & $36 \mathrm{~h}$ & $50 \mathrm{~h}$ & $70 \mathrm{~h}$ & $85 \mathrm{~h}$ & $100 \mathrm{~h}$ & $150 \mathrm{~h}$ \\
\hline 2 & 5 & 50 & 5.58 & 6.0 & 6.5 & 7.0 & 8.0 & 8.0 & 8.0 & 8.0 \\
\hline 3 & 5 & 50 & 5.58 & 5.5 & 6.0 & 6.5 & 7.5 & 8.0 & 8.0 & 8.0 \\
\hline 4 & 5 & 50 & 5.58 & 5.0 & 6.0 & 6.0 & 7.0 & 7.5 & 7.5 & 8.0 \\
\hline 2 & 5 & 50 & 5.03 & 6.5 & 7.5 & 8.5 & 9.5 & 10.0 & 10.0 & 10.0 \\
\hline 3 & 5 & 50 & 5.03 & 6.0 & 7.0 & 8.0 & 9.0 & 10.0 & 10.0 & 10.0 \\
\hline 4 & 5 & 50 & 5.03 & 6.0 & 6.5 & 7.0 & 8.5 & 9.0 & 10.0 & 10.0 \\
\hline $2,3,4$ & 5 & 50 & 3.09 & \multicolumn{7}{|c|}{ No changing occurs in the gel volume } \\
\hline 3 & 5 & 50 & 2.01 & 4.5 & 4.0 & 3.5 & - & 3.0 & 3.0 & 3.0 \\
\hline 4 & 5 & 50 & 2.01 & 4.5 & 4.5 & 4.0 & - & 3.5 & 3.0 & 3.0 \\
\hline
\end{tabular}

Table 5. The maximum swelling of copper-alginate gel membranes in universal buffer solution.

\begin{tabular}{ccc}
\hline pH of solvent & $\begin{array}{c}\text { Volume of gel, } \\
\mathbf{c m}^{\mathbf{3}}\end{array}$ & $\begin{array}{c}\text { Maximum change in } \\
\text { the gel volume } \mathbf{( c m}^{\mathbf{3}} \mathbf{)}\end{array}$ \\
\hline 2.10 & 5 & 3.3 \\
3.09 & 5 & 5.0 \\
4.01 & 5 & 7.5 \\
5.03 & 5 & 10.0 \\
5.38 & 5 & 9.0 \\
5.58 & 5 & 8.0 \\
6.50 & 5 & 7.0 \\
7.50 & 5 & 5.0 \\
\hline
\end{tabular}

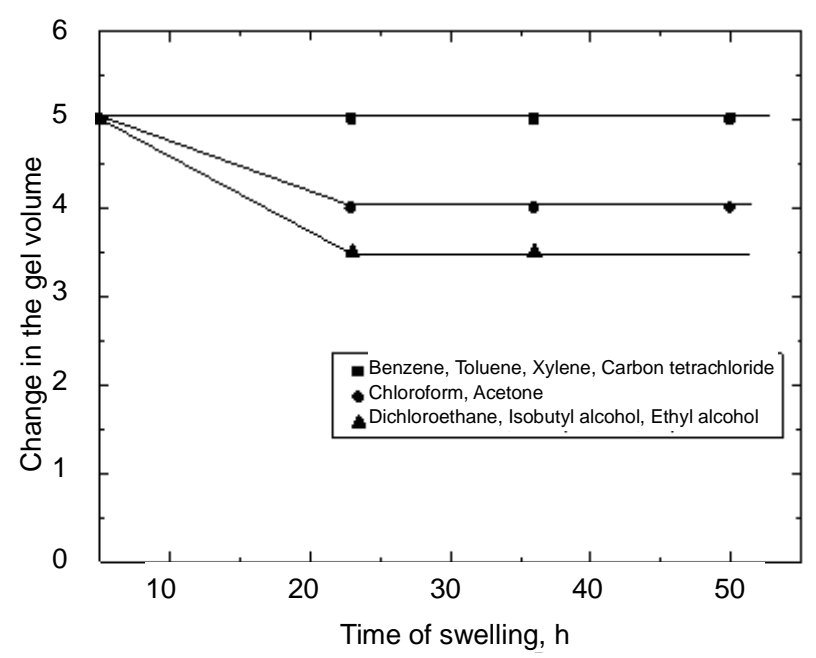

Figure 1. Plots of swelling versus time in different solvents.

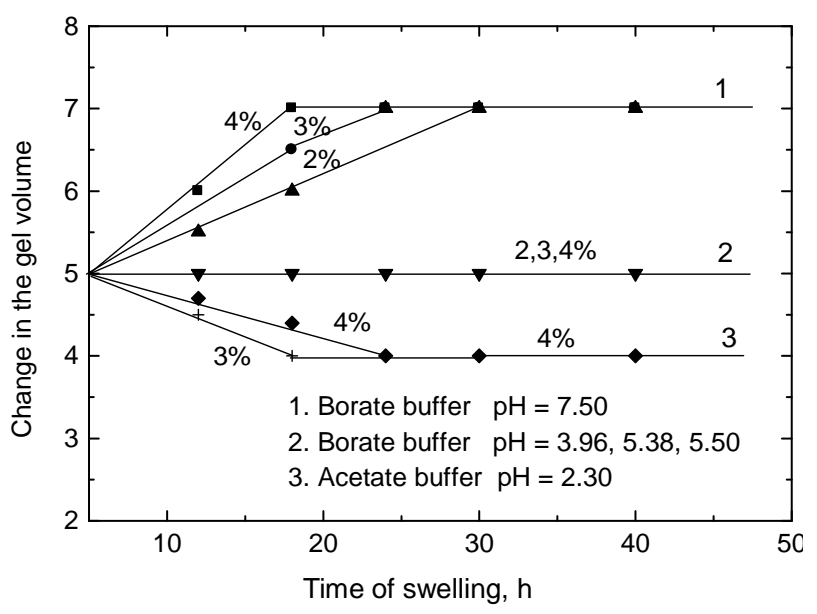

Figure 2. Plots of swelling versus time in buffer solutions.

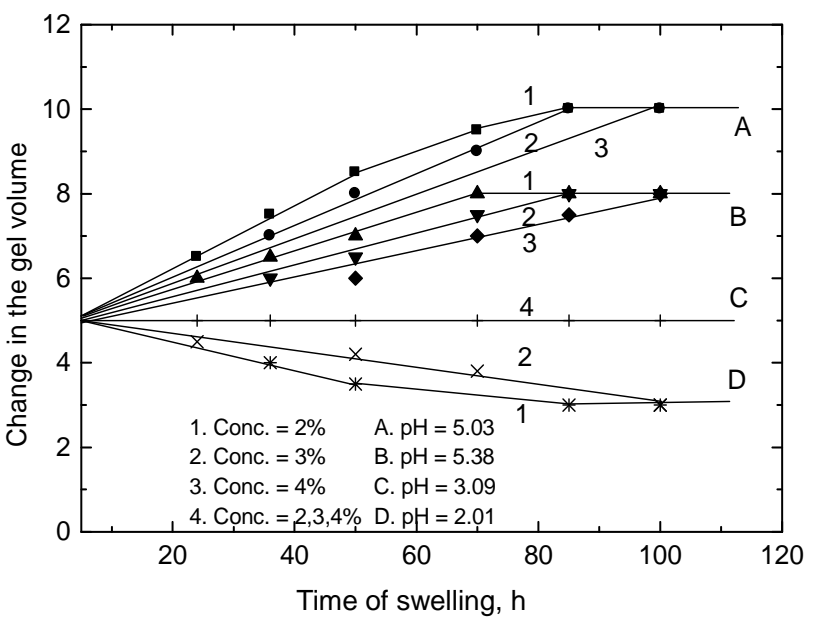

Figure 3. Plots of swelling versus time at different values. 
Table 6. The behavior of different metal-alginate spheres in universal buffer solutions $(\mathrm{pH}=5.33)$.

\begin{tabular}{|c|c|c|c|c|c|c|}
\hline \multirow{2}{*}{ Metal-alginate } & \multirow{2}{*}{ Concn. of gel (\%) } & \multirow{2}{*}{ Volume of gel, $\mathrm{cm}^{3}$} & \multirow{2}{*}{ Volume of solution, $\mathrm{mL}$} & \multicolumn{3}{|c|}{ Changing in the gel volume $\left(\mathrm{cm}^{3}\right)$ with time $/ \mathrm{h}$} \\
\hline & & & & $24 \mathrm{~h}$ & $68 \mathrm{~h}$ & $164 \mathrm{~h}$ \\
\hline Ca-alginate & 4 & 40 & 50 & 6.5 & 7.5 & 8.5 \\
\hline Cu-alginate & 4 & 40 & 50 & 7.5 & 10.0 & 10.5 \\
\hline Zn-alginate & 4 & 40 & 50 & 6.0 & 6.5 & 7.0 \\
\hline Ba-alginate & 4 & 40 & 50 & 7.0 & 8.0 & 9.0 \\
\hline Ca-alginate & 4 & 40 & 50 & 5.5 & 6.0 & 6.0 \\
\hline
\end{tabular}

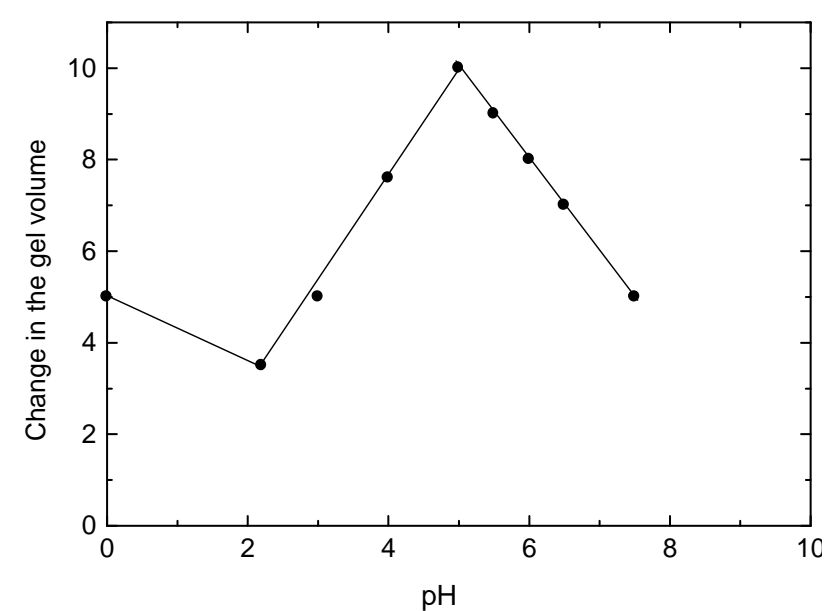

Figure 4. Effect of $\mathrm{pH}$ on the change of hydrogel volume.

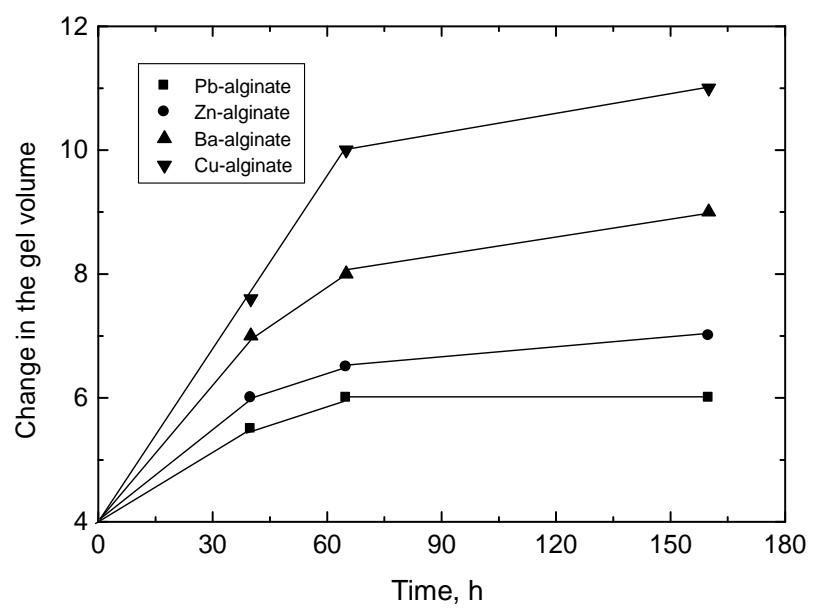

Figure 5. Plots of swelling versus time for various metal-alginate hydrogel biopolymeric complexes in universal buffer solutions.

\subsection{Gravimetric Analysis}

Gravimetric analysis technique was used in order to determine the stoichiometric molar ratio of the (metal: alginate) in these cross-linked metal-alginate ionotropic hydrogels. This technique was based on the results obtained from the TGA data [19-22]. Therefore, ionotropic metal-alginate hydrogels in the sphere forms were heated at about $105^{\circ} \mathrm{C}$ for about 5 - $10 \mathrm{~h}$ until constant volume in order to evaluate the water content. Then, the dried spheres were heated after their corresponding decomposition temperatures (obtained from TGA data) for about $24 \mathrm{~h}$ in order to convert these unhydrous metal alginate gels to its corresponding metal oxides as final products. The stoichiometric molar ratios can be evaluated from the weights of unhydrous metal-alginate spheres and the weight of the final metal oxides.

\section{RESULTS AND DISCUSSION}

\subsection{Stoichiometry}

Ion exchange is inherently a stoichiometric process [29]. This means that, the $\mathrm{Na}^{+}$counter ions which leave the macromolecular chains outward to the electrolyte solution during the gelation process must be replaced by an equivalent amount of the metal ions diffused from the electrolyte solutions inward to the alginate sol, i.e. the fluxes of the two exchanging counter ions should be equal in magnitude even the mobilities and valencies of the two counter ions may be different.

The experimental results obtained from the gravimetrical analysis indicated that one mole of the divalent metal ion chelates two moles of alginate macromolecule monomers $\left(\mathrm{Alg}^{-}\right)$. This result conforms to the following stoichiometric overall reactions

$$
\begin{gathered}
2(\mathrm{Na}-\mathrm{Alg})_{\mathrm{n}}+\mathrm{nM}^{2+}=\left(\mathrm{M}-\mathrm{Alg}_{2}\right)_{\mathrm{n}}+\left(2 \mathrm{Na}^{+}\right)_{\mathrm{n}} \\
\text { sol electrolyte gel electrolyte }
\end{gathered}
$$

where $\mathrm{Na}-\mathrm{Alg}$ and $\mathrm{M}-\mathrm{Alg}_{2}$ denote the sodium alginate sol and its corresponding cross-linked metal-alginate hydrogel and $\mathrm{M}$ is the metal. The molar stoichiometric ratios obtained here were found to be in good agreement with that observed in other kinetic studies [9-12].

Again, the TGA curves showed three steps of weight loss [19-22]. The first stage involves the dehydration of the coordinated water molecules $\left(\mathrm{X} \cdot \mathrm{H}_{2} \mathrm{O}\right)$. The second stage corresponds to the formation of oxalate intermediate fragments, whereas the third one represents to the decomposition of the oxalate intermediate fragments with the formation of metal oxides as final decomposi 
tion products as follows

Metal-alginate $\cdot \mathrm{XH}_{2} \mathrm{O}=$ Metal-alginate $+\mathrm{XH}_{2} \mathrm{O}$ (first stage)

Metal-alginate $=$ Metal oxalate fragments $+\mathrm{CO}_{2}+\mathrm{H}_{2} \mathrm{O}$

(second stage)

Metal oxalate $=$ Metal oxide $+\mathrm{CO}_{2}+\mathrm{H}_{2} \mathrm{O}($ third stage $)$

The number of coordinated water molecules along with the percent of water contents, rates of gelation and other rheological properties are summarized in Table $\mathbf{1 .}$

\subsection{Mechanism of Gelation}

\subsubsection{Cross-Linked Metal-Alginate Membranes}

As the alginate sol comes in contact with the metal ion electrolyte, a primary membrane is rapidly formed on the surface of alginate sol placed inside the Petri-dishes. This formed membrane will prevent the alginate sol from deterioration or scattering into the electrolyte solution. Afterwards, an exchange process will take place between the leaving $\mathrm{Na}^{+}$counter ions from its alginate macromolecule outward to the electrolyte solution with a simultaneous diffusion of metal cations from its electrolyte solution inward to the alginate sol.

\subsubsection{Cross-Linked Metal-Alginate Spheres}

As the alginate sol droplet comes in contact with the metal ion electrolyte, a primary membrane is rapidly formed around the alginate sol droplet. This formed membrane will keep the alginate sol droplet in spherical shape as well as prevents the alginate sol inside the droplet from deterioration or scattering onto the external metal-ion electrolyte solution. At the beginning, the alginate sol droplet will float as just below the surface of metal ion electrolyte because its density is less than that of the metal ion electrolyte. Then, an exchange process will take place between the $\mathrm{Na}^{+}$counter ions of alginate macromolecule and the metal cations of the electrolyte through that formed primary membrane. When the density of the droplet exceeds that of the electrolyte, it begins to sink into the electrolyte by a certain velocity which can be termed as the velocity of acceleration. The time consumed between the floating and sinking of the droplet may be called the relaxation time $(\Delta \mathrm{T})$. Both relaxation time and velocity of acceleration were found to be dependent on the nature of the metal ion (such as its mass, density, radius, concentration and $\mathrm{pH}$ 's of both the alginate sol and electrolyte solutions) as well as on the temperature $[13,14]$. The relaxation time and the rate of gelation along with some other rheological properties are summarized in Table 1. Again, the mechanism of sol-gel transformation for these ionotropic cross-linked metal alginate spheres was explained in more detailed earlier [9-12].

The exchange process (replacement of $\mathrm{Na}^{+}$counter ions by metal ions) leads to the well-known sol-gel transformation phenomenon with formation of corresponding ionotropic cross-linked metal alginate hydrogels. Here, a sort of bridges is formed between the interdiffused metal ions and the carboxylate and hydroxyl functional groups present on the monomers of the alginate macromolecular chains through formation of partially ionic and partially coordinate bonds, respectively. In reality, these bonds are not just simple, but a kind of chelates involving one pair of carboxylate groups and one or more pairs of hydroxyl groups are formed in an egg-carton like structure [30]. The number of $\mathrm{OH}$ groups depends on the coordination number of chelated metal ion. The coordination geometry in these ionotropic hydrogels were discussed in more detailed by Hassan earlier [31]. The geometrical configuration of these cross-linked ionotropic metal-alginate hydrogels is illustrated in Scheme I.

\subsection{Gel Morphology}

These cross-linked metal-alginate gels were characterized by a distinct morphological-structure depending on the direction of diffusion of metal cations towards the alginate sol in order to replace the leaving $\mathrm{Na}^{+}$counter ions. When the metal ions are allowed to diffuse upward such as in case of columns (where one side of the column was previously closed with a cellophane paper and filled with alginate sol) immersed in electrolyte solution, non-capillary structural gels were formed. This method of gel preparation is called "ascending technique" [15, $16,27]$. On the other hand, as the metal ions are diffused downward such as in case of spheres and membrane hydrogels, the direction of diffusion becomes trappingcapillaries that are parallel and symmetrically identical. This later method is termed "descending technique" $[28,32]$. When a traverse section is made in the capillary zone of the formed hydrogel, a porous structure image is obtained. The formed pores seem to be identical and with the same diameters and sizes [12,28]. This kind of gels possesses an anisotropic property owing to the orientation of the solvent molecules and the macromolecular chains toward the chelated metal ions. This property is mainly depending on the nature of metal ion used [7,33,34]. Some optical and microscopical scanning in some metal-alginate hydrogel complexes are shown in Image I [12,17,18,28].

The suffered change in volume for copper-alginate membrane cubes $(4 \%)$ immersed in organic solvents for about $120 \mathrm{~h}$ are shown in Table 2 and Figure 1. However, the non-polar solvents showed no change in the 


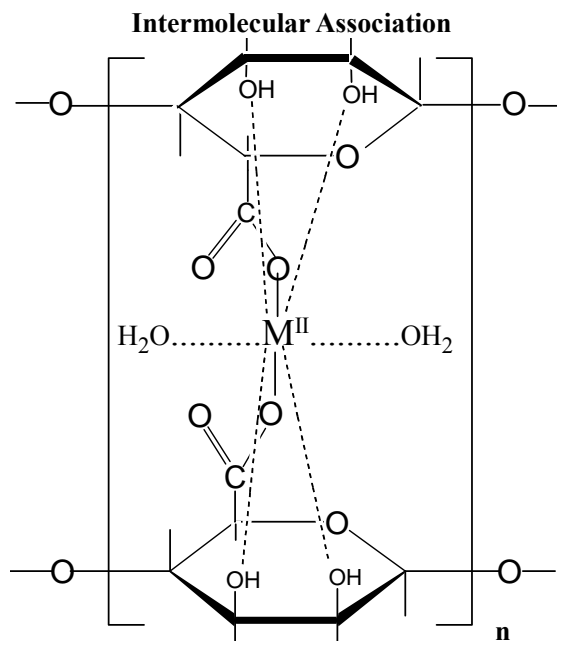

Intramolecular Association

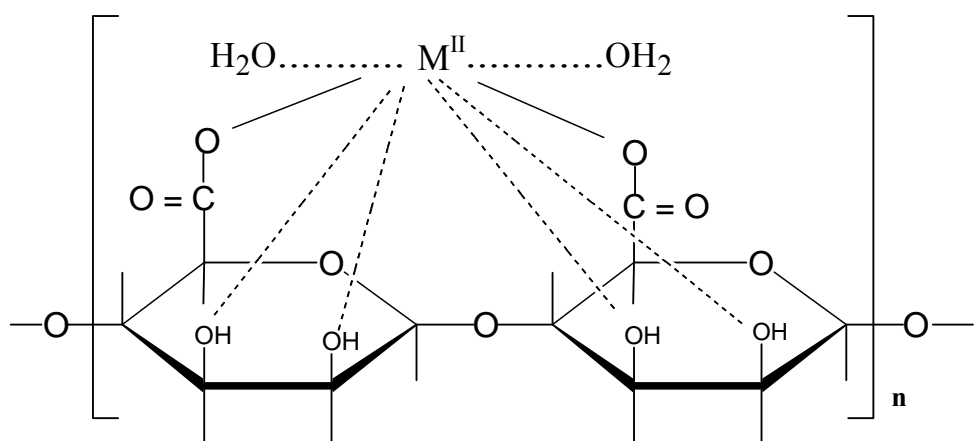

Scheme I. Geometrical configuration in cross-linked divalent metal-alginate biopolymeric complex.

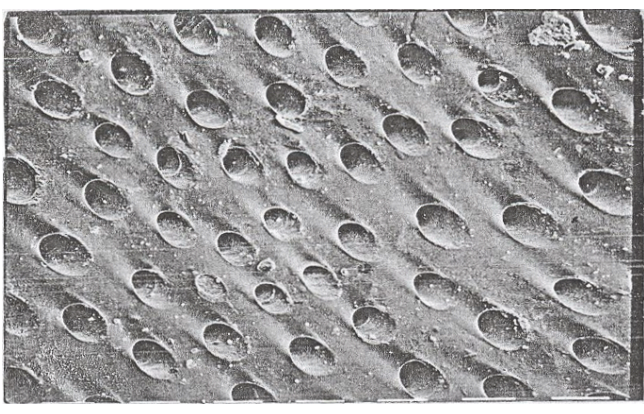

(a)

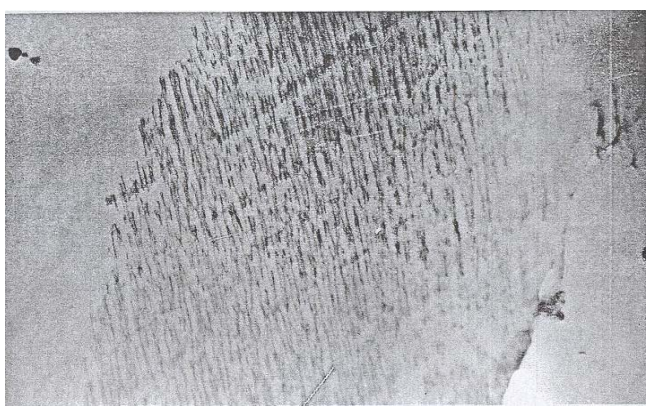

(c)

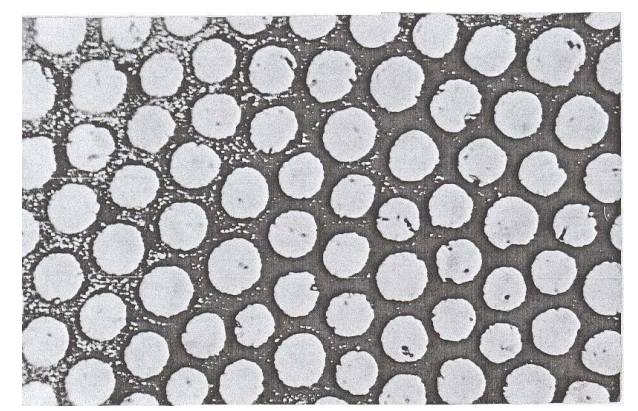

(b)

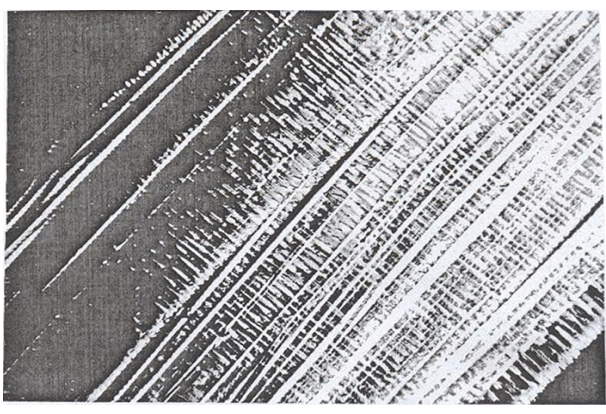

(d)

Image I. Optical photos of pore size (a), (b) SEM and (c) and TEM (d) of polymembrane images in cross-linked metal (II)-alginate hydrogel complexes. 
physical properties of gels, a remarkable shrinking of the gels was observed in case of polar-solvents. On the other hand, the hydrogel shrinkage or swelling was found to be $\mathrm{pH}$-dependent of the buffer used in case of buffer solutions. It seems that the dielectric constants or polarity of the organic solvents used have no influence on such properties, i.e. it agrees with that observed by Torres et al. [4] for calcium-alginate spheres.

Generally, these hydrogels tend to equilibrate with its external solvents. Therefore, the swelling property observed may be attributed to the tendency of the ionogenic groups of the monomeric units (carboxylate and hydroxyl moieties) to surround themselves by some solvent molecules which causes a stretching of the alginate matrix. As an equilibrium condition is attained, the elastic forces of the matrix will balance with the absorption tendency and, hence, the matrix expansion is stopped.

In case of the polar-solvents, the observed shrinking can be explained by a desorption phenomena where some water molecules should be released from the gel matrix to the external solution in order to preserve the gel in an equilibrium state with that external solvent. But in case of non-polar solvents, no change in volume or other properties was observed. This behavior may be attributed to the inhibition phenomena in which the water content in the gel matrix is just replaced by the solvent molecules with no expansion of the gel matrix.

As shown in Tables 3-5 and Figures 2-5, the swelling and shrinking properties of copper-alginate polymem- branes in the buffer solutions are mainly dependent on the $\mathrm{pH}$ of the buffer used. For example, the hydrogels tend to swell at moderate of $\mathrm{pHs}(5.03-5.08)$, but tend to shrink at the lower pHs (2.03) in the universal buffer as shown in Tables $\mathbf{4}$ and $\mathbf{5}$. In the former case, the swollen effect may be attributed to the tendency of the gels to equilibrate with the external buffer solution and, hence, this property is attained by the gel sorption of some buffer molecules. The swelling process will cease gradually with time until it stops completely as the equilibrium is reached between the hydrogel matrix and the external buffer solution. The ability of the hydrogels to swelling was found to be more pronounced in the gels of lower alginate concentrations rather than that of the gels of higher concentrations. In the second case at lower $\mathrm{pHs}$, the equilibrium between the gel and the external buffer solution is attained by a desorption process for some water molecules from the inside the gel to its outside onto the external buffer solution. The change in volume as a function of $\mathrm{pH}$ is shown in Table 5 and Figure 4, respectively. This behavior indicates that the $\mathrm{pH}$ of the buffer solution plays an important role in the change property of the gel volume. As the $\mathrm{pH}$ of the buffer decreases the capillary width of the gel zones becomes more narrows and, hence, a decrease in the gel volume is observed (shrinking) $[27,28]$. On the other hand, the increase of the $\mathrm{pH}$ of the buffer will lead to an increase in the capil lary width of the gel zone, i.e. the volume of the gel increases (swelling). For higher $\mathrm{pHs} \geq 10$, the hydrogels

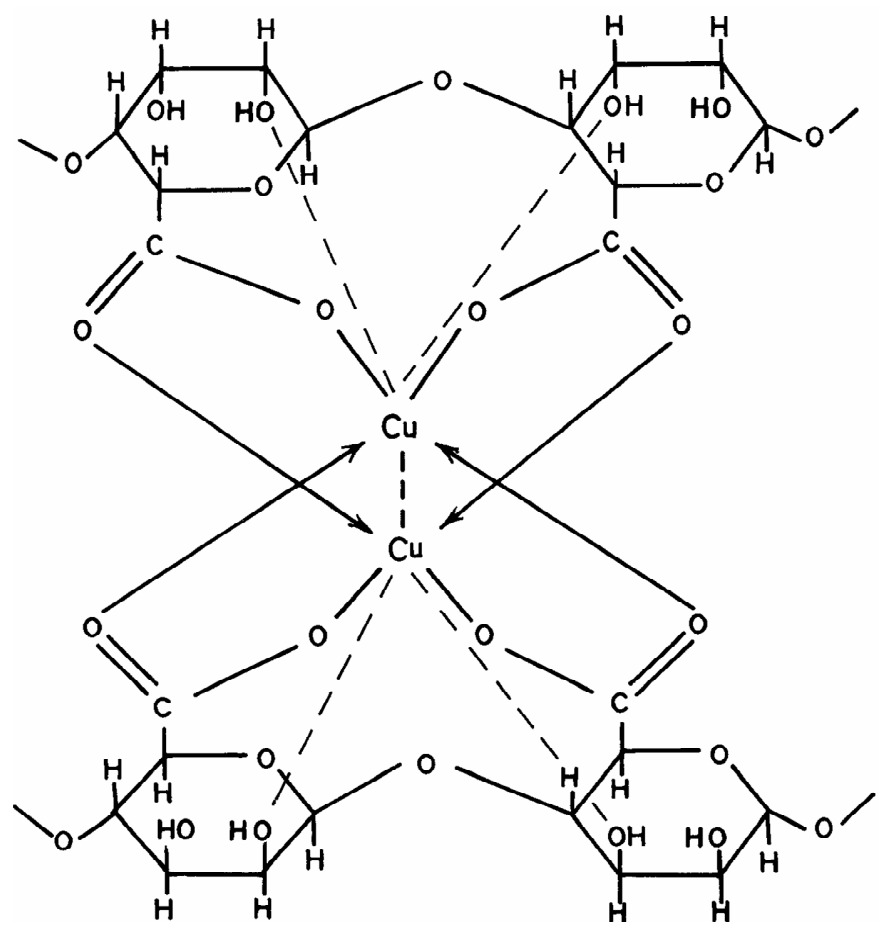

Scheme II. Distorted octahedral structure in cross-linked copper (II)alginate biopolymeric complex. 
tend to deteriorate.

In buffer solutions of moderate pH's (3.09), since equilibrium is already existed between the gel membrane and the buffer solution, no change in the gel properties was observed. The maximum sorption was noticed at $\mathrm{pHs}=5.03$. Therefore, the swelling extent for some metal-alginates of spherical shapes was examined. The results are shown in Table 6 and Figure 5, respectively. The swelling extent was found to decrease in the order $\mathrm{Cu}>\mathrm{Ba} \approx \mathrm{Ca}>\mathrm{Zn}>\mathrm{Pb}$-alginate hydrogel spheres. This result may ascribe the nature of the counter ions, i.e. the mechanical stability and strength of the chelated bonds as well as the geometrical configuration of the gel formed. The good mechanical stability observed in copper-alginate hydrogel compared to other metal-alginates may be attributed to the great extent of orientation as well as to its distorted octahedral structure (Scheme II) $[13,28]$.

\section{REFERENCES}

[1] Ozeroglu, C. and Birdol, A. (2009) Swelling properties of acrylamide-N,N-methylene bis (acrylamide) hydrogel synthesized by using meso-2,3-dimercaptosuccinic acidcerium (IV) redox couple. Express Polymer Letter, 3, 168176. doi:10.3144/expresspolymlett.2009.22

[2] Saha, N., Saarai, A., Ray, N., Kilano, T. and Shasaha, P. (2011) Polymeric biomaterial based hydrogels for biomedical application. Journal of biomaterial nanotechnology, 2, 85-90.

[3] Torres, L.G., Sanchez-de-la-Vega, A., Beltran, N.A. and Jimenez, B.E. (1998) Production and characterization of a Ca-alginate biocatalyst for removal of phenol and chlorophenols from wastewaters. Process Biochemistry, 33, 625634. doi:10.1016/S0032-9592(98)00026-0

[4] Torres, L.G., Velasquez, A. and Brito-Arias, M.A. (2011) Ca-alginate spheres behavior in presence of some solvents and water-solvent mixtures. Advances in Bioscience and Biotechnology, 2, 8-12. doi:10.4236/abb.2011.21002

[5] Schweiger, R. (1962) Acetylation of alginic acid. II. Reaction of algin acetates with calcium and other divalent ions. Journal of Organic Chemistry, 27, 1789-1791. doi:10.1021/jo01052a073

[6] Haugh, A. and Smidsrod, O. (1965) The effect of divalent metals on the properties of alginate solution. I \& II Calcium ions. Acta Chemica Scandinavica, 19, 341. doi:10.3891/acta.chem.scand.19-0341

[7] Thiele, H. and Awad, A. (1966) Ions and their biological effects. Investigation on ionotropic gels. Biotechnology, 3, 63-75.

[8] Awad, A., El-Cheikh, F. and Hassan, R.M. (1979) Kinetics of sol-gel transformation especially ionotropic gels. Revue Roumaine de Chimie, 2, 8-12.

[9] Hassan, R.M., Wahdan, M.H. and Hassan, A. (1988) Kinetics and mechanism of sol-gel transformation on polye- lectrolytes of nickel alginate ionotropic membranes. European Polymer Journal, 24, 281-283. doi:10.1016/0014-3057(88)90223-6

[10] Hassan, R.M., El-Shatoury, S.A., Mousa, M.A. and Hassan, A. (1988) Kinetics and mechanism of sol-gel transformation for polyelectrolytes of capillary copper alginate ionotropic membranes. European Polymer Journal, 24, 1173 1175. doi:10.1016/0014-3057(88)90106-1

[11] Hassan, R.M., Summan, A.M., Hassan, M.K. and ElShatoury, S.A. (1989) Kinetics and mechanism of sol-gel transformation on polyelectrolytes of some transition metal ions especially cobalt alginate ionotropic membranes. European Polymer Journal, 25, 1209-1212. doi:10.1016/0014-3057(89)90083-9

[12] Khairou, K.S., El-Gethami, W.M. and Hassan, R.M. (2002) Kineticsand mechanism of sol-gel transformation between sodium alginate polyelectrolyte and some heavy divalent metal ions with formation of capillary polymembranes ionotropic gels. Journal of Membrane Science, 209, 445-465. doi:10.1016/S0376-7388(02)00353-8

[13] Hassan, R.M., Makhlouf, M.Th. and El-Shatoury, S.A. (1992) Alginate polyelectrolyte ionotropic gels. IX. Diffusion control effects on the relaxation time of sol-gel transformation of divalent metal alginate ionotropic gel complexes. Colloid and Polymer Science, 12, 1237-1242. doi:10.1007/BF01095065

[14] Khairou, K.S., Al-Gethami, W.M. and Hassan, R.M. (2003) Diffusion controls influence on relaxation time and velocity of acceleration of sol-gel transformation for cross-linked metal alginate ionotropic gel complexes. Bulletin of Polish Academic of Sciences, 51, 209-220.

[15] Hassan, R.M. (1989) Influence of frequency on electrical properties of acid and trivalent metal alginate ionotropic gels. A correlation between strength of chelation and stability of polyelectrolyre gels high perform. Polymer, 1, 275-284.

[16] Hassan, R.M., Makhlouf, M.Th. and Summan, A.M. (1989) Influence of frequency on specific conductance of polyelectrolyte gels with special correlation between strength of chelation and stability of divalent metal alginate ionotropic gels. European Polymer Journal, 25, 993-996. doi:10.1016/0014-3057(89)90126-2

[17] Hassan, R.M. (1991) Alginate polyelectrolyte ionotropic gels. III. Kinetics of exchange of chelated divalent transition metal ions especially cobalt (II) and copper (II) by hydrogen ions in capillary ionotropic metal alginate polymembrane gels. Journal of Material Science, 26, 58065810. doi:10.1007/BF01130118

[18] Hassan, R.M. (1991) Alginate polyelectrolyte ionotropic gels. Part II: Kinetics and mechanism of exchange of chelated nickel (II) by hydrogen ions in capillary ionotropic nickel-alginate polymembrane gel complex. Journal of Material Science, 28, 384-388. doi:10.1007/BF00357813

[19] Said, A.A. and Hassan, R.M. (1993) Thermal decomposition of some divalent metal alginate gel compounds. Journal of Polymer Degradation Stability, 39, 393-397. doi:10.1016/0141-3910(93)90015-B 
[20] Khairou, K.S. (2002) Kinetics and mechanism of the non-isothermal decomposition of some divalent crosslinked metal alginate ionotropic gels. Journal of Thermal and Calorimetry, 69, 583-588. doi:10.1023/A:1019920108863

[21] Said, A.A., Abd El-Wahab, M.M. and Hassan, R.M. (1994) Thermal and electrical studies on some metal alginate compounds. Thermochimica Acta, 233, 13-24. doi:10.1016/S0040-6031(99)80002-1

[22] El-Gahami, M.A., Khairou, K.S. and Hassan, R.M. (2003) Thermal decomposition of $\mathrm{Sn}(\mathrm{II}), \mathrm{Pb}(\mathrm{II}), \mathrm{Cd}(\mathrm{II})$ and $\mathrm{Hg}(\mathrm{II})$ cross-linked metal-alginate complexes. Bulletin of Polish Academic Science, 51, 105-113.

[23] Khairou, K.S. and Hassan, R.M. (2002) Temperature-dependence of electrical conductivity for cross-linked monoand divalent metal alginate complexes. High Performance Polymer, 14, 93-99. doi:10.1177/0954008302014001092

[24] Zaafarany, I.A., Khairou, K.S. and Hassan, R.M. (2010) Physicochemical studies on some cross-linked trivalent metal-alginate complexes especially the electrical conductivity and chemical equilibrium related to the coordination geometry. High Performance Polymer, 22, 69-81. doi: $10.1177 / 0954008308095287$

[25] Zaafarany, I.A., Khairou, K.S., Hassan, R.M. and Ikeda, Y. (2009) Physicochemical studies on cross-linked thorium(IV)-alginate complex especially the electrical conductivity and chemical equilibrium related to the coordination geometry. Arabian Saudi Journal, 2, 1-10.

[26] John, A.D. (1979) Langes handbook of chemistry. 11th Edition, McGraw-Hill Co., New York.
[27] Hassan, R.M., El-Shatoury, S.A. and Makhlouf, M.Th. (1992) Alginate polyelectrolyte ionotropic gels. XII. Chromatographic separation of metal ions in mixture solutions. High Performance Polymer, 4, 49-54. doi:10.1088/0954-0083/4/1/006

[28] Hassan, R.M., Awad, A. and Hassan, A. (1991) Separation of metal alginate ionotropic gels to polymembranes with especial evidence on the position of chelation in copper alginate complex. Journal of Polymer Science A, 29, 1645-1648. doi:10.1002/pola.1991.080291115

[29] Hellferich, F. (1962) Ion Exchange. McGraw-Hill, New York.

[30] Rees, D.A. (1972) Polysaccharide gels, a molecular view. Chemical Industry, 630-636.

[31] Hassan, R.M. (1993) Alginate polyelectrolyte ionotropic gels. XIII. Geometrical aspects for chelation in metal alginate complexes related to their physico-chemical properties. Polymer International, 31, 81-86. doi:10.1002/pi.4990310112

[32] Thiele, H. and Hallich, K.H. (1957) Capillary structure in ionotropic gels. Kolloid-Zeitschrift, 151, 1-12. doi:10.1007/BF01502248

[33] Obolonkova, E.M., Belavtseva, E.M., Braudo, E.E. and Tolstoguzov, V.B. (1974) Formation and structure of ionotropic gels. II. Electron microscopic investigation of anisotropic calcium-alginate gels. Colloid Polymer Science, 252, 526-529. doi:10.1007/BF01558145

[34] Tolstoguzov, V.B. (1974) I. Ionotropic gels of a laminated structure. Colloid and Polymer Science, 253, 109113. doi:10.1007/BF01775674 